\title{
Prelog Medal 2007 \\ Laudatio for Scott Denmark
}

\author{
Albert Eschenmoser ${ }^{\star}$
}

I was asked by the chairman of the Institut für Organische Chemie, Erik Carreira, to present the Prelog-Medal Laudatio for my former PhD student Scott Denmark. It is with great pleasure that I do this. The situation is quite a special one; special in the sense that our medalist finds himself sandwiched between his former undergraduate student Erik Carreira and his former teacher, his Doktorvater. A rare constellation indeed.

Let me first say how delighted I was when I heard that Scott had been proposed and chosen by the Institutsleitung as this year's Prelog medalist. It creates great satisfaction for a teacher when, in his later years, he can witness the success of one of his a former students. This is why, Scott, I not only want to most cordially congratulate you, but also 'thank' you for having reached in your scientific career a level that brings you back to ETH as a Prelog medalist.

I may be allowed to indulge a little in history before I come to science.
Scott is an 'experienced medalist': he had already won two gold medals and one bronze medal in secondary school of his home town Lynbrook (N.Y.) in annual science exhibitions. In 1975, at MIT, he earned the bachelor degree in science with honors as an 'outstanding undergraduate', winning a Sigma Chi Award. This, apparently, gave him the necessary courage to visit famous Professor R.B. Woodward at neighboring Harvard University and ask him about the possibility of working for a PhD. Woodward's advice to young Denmark was the following: go first to ETH, get there your $\mathrm{PhD}$, and then return to Harvard as a postdoc in my group. And so, Scott Denmark arrived at ETH with what was, I think to remember, a "remarkable degree of selfconfidence". He declared: "not a problem in natural product synthesis is what I want, what I would like is a problem in reactivity and mechanism". And that is what he got.

Needless to say, he turned out to be brilliant in mechanisms; not surprisingly so be- cause, after all, he came from America. But - astonishingly - he was equally brilliant in performing experiments, in spite of the fact that he came from America. Importantly and luckily, in spite as well as because of his brilliance he was popular and very much liked in the group. And most importantly: although having to struggle with a hard, demanding and often disappointing problem in the lab, he experienced, so I think, his European doctorate as a happy time.

The way Scott performed already in his thesis adumbrated what in later years he became known and admired for by his peers, namely, to be a chemist who combines intuitional originality and a sharp intellect with highest experimental standards, a chemist whose attitude toward science as a whole invokes a degree of pathos, nourishing a contagious enthusiasm for research that captivates the young. Quite naturally then, he is a great teacher. In his research, he combines the pragmatism of the synthetic chemist with a platonic sense of searching for the fundamentals. When it comes to un-
${ }^{*}$ Correspondence: Prof. Dr. A. Eschenmoser ETH Zürich

Laboratorium für Organische Chemie

Wolfgang-Pauli-Str. 10

$\mathrm{CH}-8093$ Zürich

The Scripps Research Institute

10550 North Torrey Pines Rd.

La Jolla, CA 92037

E-mail: eschenmoser@org.chem.ethz.ch

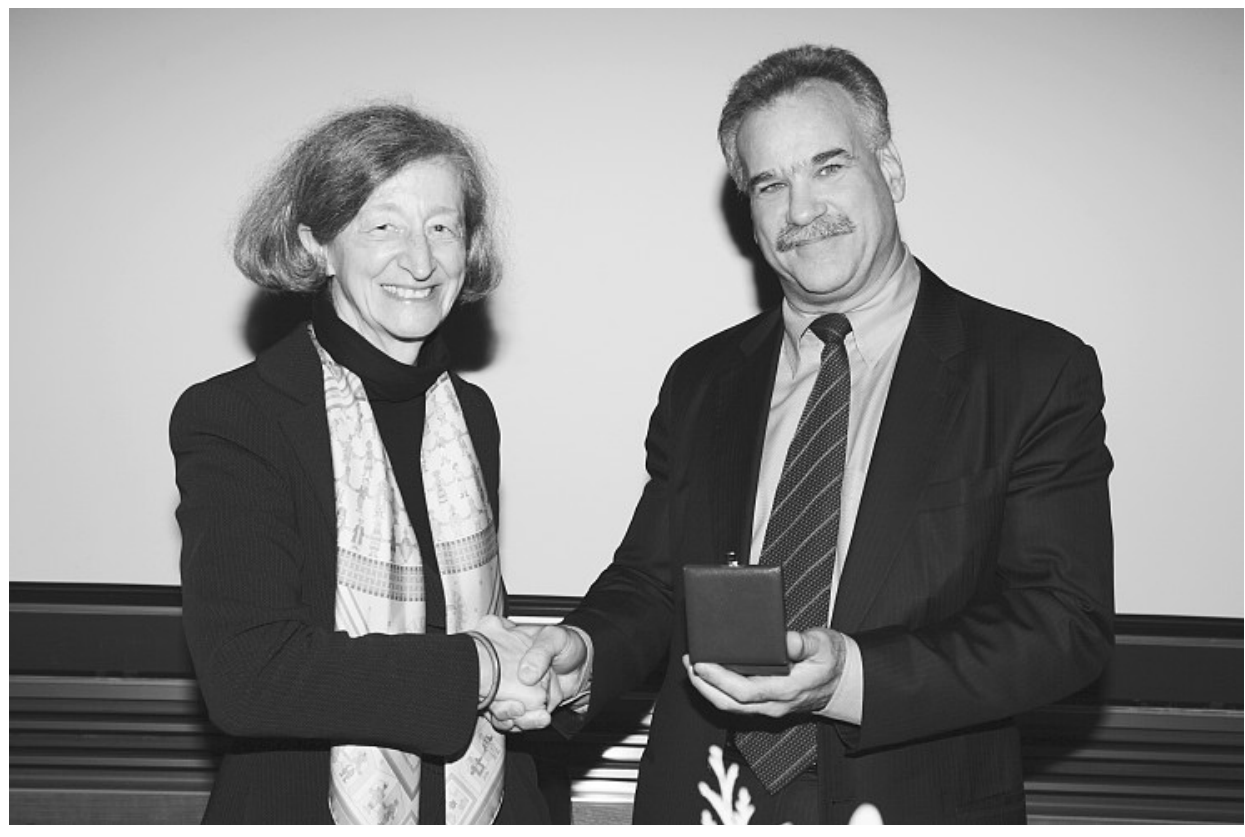

Heidi Wunderli-Allenspach and Scott E. Denmark (Photo R. Häfliger) 


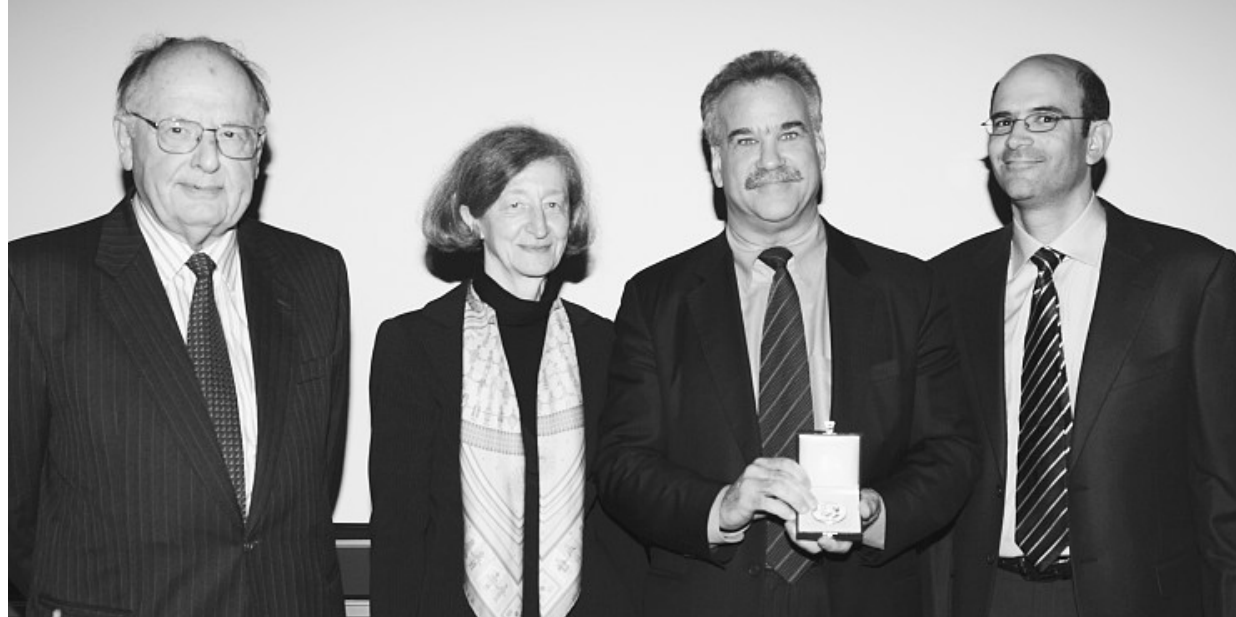

Albert Eschenmoser, Heidi Wunderli-Allenspach, Scott E. Denmark, and Eric M. Carreira (Photo R. Häfliger)

derstanding mechanistic organic chemistry on a qualitative, that is, organic level, he has a status that may well be second to none within his generation.

Scott has reached this status in spite of, or perhaps because of, the fact that - in choosing research problems - he is what biologically oriented organic chemists tend to refer to as 'aseptic'. He consciously resists the contemporary trend to become more and more biological, he follows what he considers to be his true interest, talent and destination; he tends to avoid joining mainstreams.

This is an important point: neither biology nor chemistry would be served best by a development in which all organic chemists would simply become biological such that, as a consequence, research at the core of organic chemistry and, therefore, progress in understanding the reactivity of organic molecules, would dry out. Progress at its core in understanding and reasoning is not only essential for organic chemistry itself, but for life science as a whole. Life science needs an Organic Chemistry that remains strong.

Erik Carreira has aptly summarized our medalist's research achievements in the flyer to this lecture event, such that I can focus on special aspects. After his $\mathrm{PhD}$ in 1980, when Scott started his independent academic career as a assistant professor at the University of Illinois (he could not return to Harvard, Robert Woodward had died one year before), he surprised the organic community with a beautifully conceived and highly successful piece of research, namely, making the Nazarov reaction (acid-catalyzed cyclization of bisvinyl-ketones to cyclopentenones) to proceed regioselectively by using bis-vinylketones in which the beta position of one of the two C,C-double bonds is substituted by a silyl group. This mechanistically as well as preparatively remarkable type of reaction remained a topic of research throughout his early career. The same is true for other well designed and equally successful topics that he had started in his earlier years, such as:

- Carbanion-accelerated Claisen rearrangements

- Cycloaddition reactions of nitrosoalkenes

- Cycloaddition reactions of nitroalkenes and - since the products of such additions are nitrones:

- Tandem nitro-alkene/nitrone cycloadditions as a route to a variety of new heterocycles and alkaloids.

In an organo-chemical research program driven by a comprehensive and incisively analytical chemical mind, stereochemistry is bound to enter the scene and to play a central role. In fact, it is for his recent fundamental studies on the stereocontrol of organic reactions that Scott Denmark is awarded the Prelog medal, for studies that are brilliant contributions to mechanistic and synthetic chemistry. At the very basis of this work lie the deeply original recogni- tion and the conceptual as well as experimental exploration of a largely unexplored catalytic potential of Lewis bases to bring about stereochemical reaction control, deeply original because the insight driving this work is at first sight radically counterintuitive. It says that in a catalytic cycle the covalent interaction of Lewis bases with an electron-accepting center can increase the electrophilicity of that center. Such a phenomenon is of course not shown by carbon as the electron-accepting center but - and this is the thread leading back to the very beginning of Scott's research career as assistant professor - it is shown by silicon, as well as many related atoms that can act as hypervalent centers. The harvest that Denmark and his collaborators collected experimentally from this insight is rich and still rapidly growing and, above all: it is truly new organic chemistry. I suppose that Scott's lecture will give us a survey of this work, so I better stop. But before ending, I want to tell him this:

The medal you will receive now from the Rektorin of ETH is not golden just on the surface, it is truly compact gold. This very fact is a fitting symbol for the quality and the scientific status of your contributions to organic chemistry.

\section{Former Prelog Lecturers}

1986 Kurt Mislow

1987 Meier Lahav and Leslie Leiserowitz

1988 K. Barry Sharpless

1989 Jeremy R. Knowles

1990 Henri B. Kagan

1991 Clayton H. Heathcock

1992 J. Michael McBride

1993 Hisashi Yamamoto

1994 Jean-Pierre Sauvage

1995 Yoshito Kishi

1996 David M.J. Lilley

1997 Günter Helmchen

1998 Lia Addadi

1999 David Evans

2000 Helmut Schwarz

2001 Robert H. Grubbs

2002 David E. Cane

2003 Andreas Pfaltz

2004 Marvin H. Caruthers

2005 Ben. L. Feringa

2006 Manfred T. Reetz 